\title{
Impact of the COVID-19 Pandemic on the US Credit Default Swap Market
}

\author{
Kirill Romanyuk (it) \\ Department of Finance, HSE University, Moscow 101000, Russia \\ Correspondence should be addressed to Kirill Romanyuk; kromanyuk@hse.ru
}

Received 29 June 2021; Accepted 25 October 2021; Published 30 November 2021

Academic Editor: Zakia Hammouch

Copyright ( $\odot 2021$ Kirill Romanyuk. This is an open access article distributed under the Creative Commons Attribution License, which permits unrestricted use, distribution, and reproduction in any medium, provided the original work is properly cited.

The COVID-19 pandemic affected the US economy at different levels. Since credit default swaps can be viewed as a default probability indicator, the article shows the credit default swap market perspective on how the US economy was hit by the pandemic. Forecasting models are built to estimate the predictability of the CDS market sectors during the pandemic, i.e., manufacturing, energy, banks, consumer goods, and services and financial sector excluding banks. Econometric tests are applied to check the uniqueness of credit default swap market sectors after the declaration of the pandemic. The results indicate that the financial sector excluding banks performed uniquely during the pandemic; i.e., the predictability of this sector dropped significantly, and the Chow breakpoint test and Wald coefficient test can identify the shift in the data after declaration of the pandemic.

\section{Introduction}

Economies do not develop in a straight line. They go through periods of growth and periods of systemic crisis. However, catastrophic events can cause nonsystemic crises. COVID19 is caused by a respiratory virus with unusual properties $[1,2]$, considering which governments initiated lockdowns and other restrictions all over the world. These measures affected the US economy at many levels, e.g., stocks [3], corporate bonds [4], and treasury yields [5]. Even COVID19 news had an impact on the US stock market [6].

This paper studies the US credit default swap (CDS) market before and during the COVID-19 pandemic. A credit default swap is a contract, transferring credit risk from a bond holder to a third party. CDS spread indicates the riskiness of a given company. If a CDS spread is getting wider, it means that market agents consider a company's probability of default to be higher. Moreover, CDS spreads indicate some credit risk information of a company better than stocks and bonds prices [7]. As a result, the impact of the COVID-19 pandemic on the US economy can be analyzed through a unique perspective of the CDS market. If there is a structural shift in the CDS data generating process after the declaration of the pandemic, then the findings in previous CDS research would be less relevant during the pandemic.

Multiple models are applied for forecasting CDS spreads in the literature, e.g., the Markov switching model [8], neural networks [9], and support vector machine [10]. However, this article is not about discovering new ways to predict CDS spreads, rather it is about estimating whether or not the COVID-19 pandemic affected the predictability of the US CDS market. An autoregression with exogenous variables, i.e., an autoregressive distributed lag (ARDL) model, is appropriate for this task because it will be easier to see what the differences are in the interconnections between variables in the periods before and during the COVID-19 pandemic, compared to machine learning techniques, which usually perform like a black box. Econometric tests can be also applied to assess the uniqueness of the CDS market during the pandemic.

\section{Methods}

2.1. Data Description. The data contain daily credit default swap spreads for 6 sectors, according to Thomson Reuters Eikon industry classification, i.e., manufacturing, energy, 
banks, other financial (the paper refers to it as the financial sector excluding banks), consumer goods (food and beverages), and services, 10 maturities each $(6 \mathrm{M}, 1 \mathrm{Y}, 2 \mathrm{Y}, 3 \mathrm{Y}, 4 \mathrm{Y}$, $5 \mathrm{Y}, 7 \mathrm{Y}, 10 \mathrm{Y}, 20 \mathrm{Y}$, and $30 \mathrm{Y}$ ) from 2010 to 2021. CDS spreads for all companies from these sectors were initially downloaded. CDS spreads are relatively small for companies in normal circumstances, but if a company is going through very difficult times with a high chance of default, then the CDS spread can be a hundred times greater than the average value, shifting a CDS spread for a sector dramatically. Companies with a significant number of missing values and outliers were removed, and 237 companies are left for the analysis. In addition, multiple exogenous variables are applied: Federal Funds Rate, 10-year US Treasuries Yield, NYMEX WTI Crude Oil Futures, USD Index, USD/CNY Exchange Rate, S\&P 500, S\&P 500 VIX, and a set of US sectoral fund indexes (NASDAQ Bank, NASDAQ Financial 100, NASDAQ Insurance, NASDAQ Real Estate and Other Financial Services, S\&P 500 Consumer Discretionary, S\&P 500 Consumer Staples, S\&P 500 Energy, S\&P 500 Financial, S\&P 500 Health Care, S\&P 500 Industrial, S\&P 500 Information Technology, S\&P 500 Materials, and S\&P 500 Real Estate).

2.2. ARDL Model. A general ARDL model is presented in equation (1). After assessing the qualities of the variables, a higher potential for further analysis was found in the first differences of the natural logarithm of the initial variables (equation (2)).

$$
y_{t}=\beta_{0}+\sum_{i=1}^{p} \beta_{i} * y_{t-i}+\sum_{l=1}^{k} \sum_{j=0}^{q} \delta_{j}^{l} * x_{t-j}^{l}+\varepsilon_{t},
$$

$$
\begin{aligned}
\Delta \ln \mathrm{CDS}_{t}= & \beta_{0}+\sum_{i=1}^{p} \beta_{i} * \Delta \ln \mathrm{CDS}_{t-i}+\sum_{l=1}^{k} \sum_{i=1}^{q} \delta_{i}^{l} * \Delta \ln x_{t-i}^{l} \\
& +\varepsilon_{t} .
\end{aligned}
$$

The following steps were taken to build each ARDL model:

(1) The optimal lag structure for the AR model is found

(2) Granger causality test is applied to estimate which variables are potentially valuable for the model

(3) The potentially valuable variable is added, and the F-test is applied to compare restricted and unrestricted models

(4) Steps 2 and 3 are repeated until there are no potentially valuable variables left

Training and testing sets are formed as shown in Table 1. Five ARDL models are constructed for each CDS maturity of each sector, giving 300 models in total $(5 \times 10 \times 6)$. This is applied in order to see whether the poor performance of a forecasting model during the COVID-19 pandemic is because of the pandemic or because of specificity of a training set, which can be observed through poor performance on other test sets. The performance is measured by root mean square error (MSE in equation (3)), mean absolute error (equation (4)), and mean absolute percentage error (equation (5)). Random walk (RW) forecasts are used as a benchmark.

$$
\begin{gathered}
\text { MSE }=\frac{1}{N} \sum_{i=1}^{N}\left(y_{t+i}-\widehat{y}_{t+i}\right)^{2}, \\
\text { MAE }=\frac{1}{N} \sum_{i=1}^{N}\left|y_{t+i}-\widehat{y}_{t+i}\right|, \\
\text { MAPE }=\frac{1}{N} \sum_{i=1}^{N}\left|\frac{y_{t+i}-\widehat{y}_{t+i} \mid}{y_{t+i}}\right|
\end{gathered}
$$

\section{Results}

The tables with the performance of forecasting models are given in the annex.

3.1. Manufacturing. The performance of the forecasting models for the manufacturing sector is shown in Tables A1-A5. Models trained on the 2014/15 and 2016/17 datasets are especially successful. CDS spreads are predictable for this sector during the COVID-19 pandemic.

3.2. Consumer Goods. The performance of the forecasting models for the consumer goods sector is shown in Tables B1-B5. Models trained on 2018/19 datasets showed poor performance on almost all testing sets. Models trained on 2016/17 datasets were the most consistent in outperforming the benchmark. CDS spreads are predictable for this sector during the COVID-19 pandemic.

3.3. Banking. The performance of forecasting models for the banking sector is shown in Tables C1-C5. The performance during the pandemic is poor. However, it is poor for all datasets. ARDL models trained on 2010/11 datasets outperform the benchmark only for 6-month, 1-year, and 2year spreads by only RMSE. The situation is identical for 2013 and 2016 test sets and similar for 2018 where forecasts for 6-month spreads outperform the benchmark by all measures. ARDL models outperform the benchmark only for 3-year spreads on the 2012 test set. For the rest test sets, ARDL models do not outperform the benchmark for any maturity. As a result, poor performance during the pandemic is not a drop in predictability due to the pandemic.

3.4. Energy. The performance of forecasting models for the energy sector is shown in Tables D1-D5. ARDL models trained on 2014/15 test sets show the worst performance but most of the models successfully outperform the benchmark. CDS spreads are predictable for this sector during the COVID-19 pandemic. 
TABLE 1: Train and test sets.

\begin{tabular}{|c|c|c|c|c|c|c|c|c|c|c|c|}
\hline \# & 2010 & 2011 & 2012 & 2013 & 2014 & 2015 & 2016 & 2017 & 2018 & 2019 & $2020-2021^{*}$ \\
\hline 1 & \multicolumn{2}{|c|}{ Train } & Test & Test & Test & Test & Test & Test & Test & Test & Test \\
\hline 2 & Test & Test & \multicolumn{2}{|c|}{ Train } & Test & Test & Test & Test & Test & Test & Test \\
\hline 3 & Test & Test & Test & Test & \multicolumn{2}{|c|}{ Train } & Test & Test & Test & Test & Test \\
\hline 4 & Test & Test & Test & Test & Test & Test & \multicolumn{2}{|c|}{ Train } & Test & Test & Test \\
\hline 5 & Test & Test & Test & Test & Test & Test & Test & Test & \multicolumn{2}{|c|}{ Train } & Test \\
\hline
\end{tabular}

*11 March 2020-10 March 2021.

TABLe 2: $p$-values from the Chow test for all sectors, 2010-2019.

\begin{tabular}{|c|c|c|c|c|c|c|}
\hline & Manufacturing (\%) & Financial excluding banks (\%) & Services (\%) & Banks (\%) & Consumer goods (\%) & Energy (\%) \\
\hline $6 \mathrm{M}$ & 48 & 0 & 0 & 48 & 53 & 37 \\
\hline $1 \mathrm{Y}$ & 45 & 0 & 1 & 45 & 57 & 85 \\
\hline $2 \mathrm{Y}$ & 48 & 0 & 2 & 48 & 35 & 4 \\
\hline $3 \mathrm{Y}$ & 17 & 0 & 9 & 17 & 40 & 2 \\
\hline $4 \mathrm{Y}$ & 17 & 0 & 32 & 17 & 30 & 1 \\
\hline $5 \mathrm{Y}$ & 45 & 0 & 63 & 27 & 19 & 1 \\
\hline $7 \mathrm{Y}$ & 12 & 0 & 63 & 12 & 35 & 2 \\
\hline $10 \mathrm{Y}$ & 32 & 0 & 67 & 32 & 57 & 7 \\
\hline $20 \mathrm{Y}$ & 72 & 0 & 38 & 72 & 64 & 20 \\
\hline $30 \mathrm{Y}$ & 64 & 0 & 21 & 64 & 63 & 21 \\
\hline
\end{tabular}

3.5. Services. The performance of forecasting models for the services sector is shown in Tables E1-E5. CDS spreads are predictable for this sector during the COVID-19 pandemic. Interestingly, ARDL models trained on 2010/11 datasets did not outperform the benchmark for any CDS spreads in 2014-2019 but did outperform it during the COVID-19 pandemic, meaning that this sector performed in the pandemic period similarly to the post-2008 crisis period.

3.6. Financial Excluding Banks. The performance of the forecasting models for the financial sector excluding banks is shown in Tables F1-F5. There are just a few cases in which ARDL models outperform the benchmark during the COVID-19 pandemic; hence, checking whether it is a drop in predictability due to the pandemic or just the poor performance of forecasting models in this sector is required. After going through all periods and all maturities, the pattern is clear; i.e., ARDL models outperform the benchmark on test sets before the pandemic but during the pandemic the performance drops.

3.7. Chow Breakpoint Test. Chow test estimates whether or not there is a breakpoint on a specific date, i.e., the null hypothesis: there is no breakpoint on a given date. This test is appropriate because there is a specific date of a potential breakpoint, 11 March 2020, when the World Health Organization declared COVID-19 a pandemic. CDS spreads of contracts with short-term maturities increased markedly on this date.

The Chow test is applied as follows. The optimal autoregression specification is found for CDS spreads of a sector in the prepandemic period (2010-2019). This specification is applied for the period from 4 January 2010 to 10
March 2021, and 11 March 2020 is used as a potential breakpoint (Table 2). The null hypothesis is rejected for all CDS maturities only in the financial sector excluding banks and for some CDS maturities in the services and energy sectors.

A 5-year period can be applied for a more detailed analysis. The same design is applied for the period 2015-2019 (Table 3). The financial sector excluding banks is the only sector where the null hypothesis is rejected, and it is rejected for all CDS maturities. As a result, the Chow test shows that 11 March 2020 was the breakpoint only for the financial sector excluding banks.

3.8. Wald Coefficient Test. The Wald test checks constraints on coefficients, i.e., the null hypothesis: coefficients are equal to given constraints. The Wald test is applied as follows. Optimal autoregression specifications are found for all CDS spreads for a full year after the declaration of the COVID-19 pandemic, and autoregression coefficients are taken for further usage as constraints for the Wald test. These specifications are then applied for CDS spreads each year from 2010 to 2019. The Wald test checks whether or not the autoregression coefficients for a particular year are similar to those in the pandemic period.

The Wald test for the manufacturing sector can be found in Table 4. The null hypothesis is rejected for all CDS spreads in 2012 and 2015-2019; it is rejected for some CDS spreads in 2011 and 2013 and 2014; and it is not rejected for any CDS spreads in 2010. Manufacturing sector CDS spreads did not perform uniquely after the declaration of the pandemic. After applying the Wald test for all sectors, the null hypothesis was rejected for all maturities for each year only for the financial sector excluding banks (Table 5). 
TABle 3: $p$-values from the Chow test for the financial excluding banks, services, and energy sectors, 2015-2019.

\begin{tabular}{lccc}
\hline & Financial excluding banks (\%) & Services & \\
\hline $6 \mathrm{M}$ & 0 & $77 \%$ & Energy \\
$1 \mathrm{Y}$ & 0 & $73 \%$ & $\mathrm{n} / \mathrm{a}$ \\
$2 \mathrm{Y}$ & 0 & $56 \%$ & $\mathrm{n} / \mathrm{a}$ \\
$3 \mathrm{Y}$ & 0 & $\mathrm{n} / \mathrm{a}$ & \\
$4 \mathrm{Y}$ & 0 & $\mathrm{n} / \mathrm{a}$ & \\
$5 \mathrm{Y}$ & 0 & $\mathrm{n} / \mathrm{a}$ & \\
$7 \mathrm{Y}$ & 0 & $\mathrm{n} / \mathrm{a}$ & \\
$10 \mathrm{Y}$ & 0 & $\mathrm{n} / \mathrm{a}$ & \\
$2 \mathrm{Y}$ & 0 & $\mathrm{n} / \mathrm{a}$ & $\mathrm{n}$ \\
$30 \mathrm{Y}$ & 0 & $\mathrm{n} / \mathrm{a}$ & $\mathrm{n} / \mathrm{a}$ \\
\end{tabular}

TABLE 4: $p$-values from the Wald test for the manufacturing sector.

\begin{tabular}{lcccccccccc}
\hline & $2010(\%)$ & $2011(\%)$ & $2012(\%)$ & $2013(\%)$ & $2014(\%)$ & $2015(\%)$ & $2016(\%)$ & $2017(\%)$ & $2018(\%)$ & $2019(\%)$ \\
\hline $6 \mathrm{M}$ & 38.3 & 5.8 & 0.0 & 58.0 & 0.5 & 0.0 & 0.0 & 0.0 & 0.0 & 0.0 \\
$1 \mathrm{Y}$ & 6.3 & 0.1 & 0.0 & 4.6 & 0.1 & 0.0 & 0.0 & 0.0 & 0.0 & 0.0 \\
$2 \mathrm{Y}$ & 93.9 & 18.3 & 1.3 & 94.0 & 0.9 & 0.0 & 0.0 & 0.1 & 0.0 \\
$3 \mathrm{Y}$ & 96.0 & 7.3 & 0.2 & 44.7 & 34.6 & 0.0 & 0.0 & 0.2 & 0.0 \\
$4 \mathrm{Y}$ & 96.9 & 16.5 & 1.1 & 45.4 & 81.1 & 0.0 & 0.1 & 0.4 & 0.0 & 0.0 \\
$5 \mathrm{Y}$ & 96.9 & 9.8 & 0.7 & 28.4 & 97.5 & 0.0 & 0.1 & 0.1 & 0.0 & 0.1 \\
$7 \mathrm{Y}$ & 93.0 & 55.0 & 0.3 & 24.8 & 92.7 & 0.0 & 0.1 & 0.1 & 0.0 & 0.0 \\
$10 \mathrm{Y}$ & 32.5 & 7.9 & 4.0 & 38.9 & 93.0 & 1.0 & 2.0 & 3.6 & 3.6 & 0.0 \\
$20 \mathrm{Y}$ & 43.3 & 2.0 & 1.9 & 13.6 & 47.5 & 0.3 & 0.7 & 1.7 & 0.0 & 2.0 \\
$30 \mathrm{Y}$ & 64.4 & 2.7 & 2.1 & 12.8 & 44.9 & 0.2 & 0.7 & 0.9 & 0.0 & 0.6 \\
\hline
\end{tabular}

TABLE 5: Wald coefficient test summary, the number of times when the null hypothesis was not rejected for CDS spreads in different years, 2010-2019.

\begin{tabular}{|c|c|c|c|c|c|c|}
\hline & Manufacturing & Financial excluding banks & Services & Banks & Consumer goods & Energy \\
\hline $6 \mathrm{M}$ & 3 & 0 & 3 & 1 & 2 & 1 \\
\hline $1 \mathrm{Y}$ & 1 & 0 & 4 & 0 & 1 & 6 \\
\hline $2 \mathrm{Y}$ & 3 & 0 & 3 & 1 & 3 & 6 \\
\hline $3 \mathrm{Y}$ & 4 & 0 & 2 & 1 & 2 & 4 \\
\hline $4 \mathrm{Y}$ & 4 & 0 & 1 & 1 & 1 & 5 \\
\hline $5 \mathrm{Y}$ & 4 & 0 & 0 & 1 & 2 & 4 \\
\hline $7 \mathrm{Y}$ & 4 & 0 & 0 & 0 & 1 & 3 \\
\hline $10 \mathrm{Y}$ & 4 & 0 & 0 & 1 & 1 & 3 \\
\hline $20 \mathrm{Y}$ & 3 & 0 & 6 & 2 & 1 & 4 \\
\hline $30 \mathrm{Y}$ & 3 & 0 & 6 & 2 & 0 & 4 \\
\hline
\end{tabular}

\section{Conclusions}

The US CDS market was analyzed in this paper. 300 ARDL models were constructed to find a drop in predictability of 6 CDS market sectors after the declaration of the COVID-19 pandemic. Such a drop was found only for the financial sector excluding banks. In addition, the Chow breakpoint test and Wald coefficient test were applied to check the uniqueness of 6 CDS market sectors after the declaration of the COVID-19 pandemic. The tests showed that only the financial sector excluding banks performed uniquely during the pandemic, which can be explained as follows. The financial sector excluding banks contains many insurance companies. Healthcare is expensive in the US, and it is mostly financed through the insurance system. A high number of COVID-19 cases appeared in the US, and COVID-19 treatment was expensive. Insurance companies were required to cover a significant part of these costs. As a result, the financial sector excluding banks became the forefront of the 2020 crisis in the US.

The unusual performance of the financial sector excluding banks means that the results for this sector obtained from analysis of 2010-2019 data are potentially less relevant after the declaration of the pandemic, and at least the performance of forecasting models is lower because of unusual patterns in CDS spreads. This does not mean that this sector will perform this way forever as the situation was caused by the pandemic. When the pandemic is over, insurance companies will not face unexpectedly high payments due to COVID-19, and the financial sector excluding banks will be more likely to perform similarly to the preCOVID-19 pandemic period. However, the other sectors did not perform uniquely during the pandemic which makes previous CDS research results more applicable after the declaration of the pandemic. 


\section{Data Availability}

The data used to support the findings of this study can be discovered in Thomson Reuters Eikon.

\section{Conflicts of Interest}

The author declares no conflicts of interest regarding the publication of this paper.

\section{Supplementary Materials}

The annex contains tables with the performance of the forecasting models for all sectors: manufacturing (A), consumer goods (B), banking $(C)$, energy $(D)$, services $(E)$, and financial excluding banks (F). (Supplementary Materials)

\section{References}

[1] W. Gao, H. M. Baskonus, and L. Shi, "New investigation of bats-hosts-reservoir-people coronavirus model and application to 2019-nCoV system," Advances in Difference Equations, vol. 391, pp. 1-11, 2020

[2] W. Gao, P. Veeresha, H. M. Baskonus, D. G. Prakasha, and P. Kumar, "A new study of unreported cases of 2019-nCOV epidemic outbreaks," Chaos, Solitons \& Fractals, vol. 138, Article ID 109929, 2020.

[3] S. Farid, G. M. Kayani, M. A. Naeem, and S. J. H. Shahzad, "Intraday volatility transmission among precious metals, energy and stocks during the COVID-19 pandemic," Resources Policy, vol. 72, Article ID 102101, 2021.

[4] M. O'Hara and X. Zhou, "Anatomy of a liquidity crisis: corporate bonds in the COVID-19 crisis," Journal of Financial Economics, vol. 142, no. 1, pp. 46-68, 2021.

[5] Z. He, S. Nagel, and Z. Song, "Treasury inconvenience yields during the COVID-19 crisis," Journal of Financial Economics, 2021, In press.

[6] S. Baek, S. K. Mohanty, and M. Glambosky, "COVID-19 and stock market volatility: an industry level analysis," Finance Research Letters, vol. 37, Article ID 101748, 2020.

[7] J. Lee, A. Naranjo, and G. Velioglu, "When do CDS spreads lead? Rating events, private entities, and firm-specific information flows," Journal of Financial Economics, vol. 130, no. 3, pp. 556-578, 2018.

[8] F. Fei, A.-M. Fuertes, and E. Kalotychou, "Dependence in credit default swap and equity markets: dynamic copula with Markov-switching," International Journal of Forecasting, vol. 33, no. 3, pp. 662-678, 2017.

[9] Y. Son, H. Byun, and J. Lee, "Nonparametric machine learning models for predicting the credit default swaps: an empirical study," Expert Systems with Applications, vol. 58, pp. 210-220, 2016.

[10] C. Luo, D. Wu, and D. Wu, “A deep learning approach for credit scoring using credit default swaps," Engineering Applications of Artificial Intelligence, vol. 65, pp. 465-470, 2017. 